\title{
High Performance of Ui0-66 Metal-Organic Framework Modified with Melamine for Uptaking of Lead and Cadmium from Aqueous Solutions
}

alaaS Abdelmoaty ( $\sim$ 3laasalah.86@gmail.com )

Inorganic Chemistry Department

Shaimaa El-Wakeel

Water Pollution Research Department

Nady Fathy

Surface and Catalysis Laboratory

AdlyA Hanna

Inorganic Chemistry Department

\section{Research Article}

Keywords: UiO-66, metal-organic framework, Modification, Melamine, Adsorption, Lead (II), Cadmium (II)

Posted Date: December 30th, 2021

DOI: https://doi.org/10.21203/rs.3.rs-1195293/v1

License: (c) (i) This work is licensed under a Creative Commons Attribution 4.0 International License.

Read Full License

Version of Record: A version of this preprint was published at Journal of Inorganic and Organometallic Polymers and Materials on April 19th, 2022. See the published version at https://doi.org/10.1007/s10904-022-02326-9. 


\section{Abstract}

In this paper, UiO-66 metal-organic framework (MOF) was prepared by a hydrothermal method and modified consequently with melamine (MUiO-66), as so as enhance the adsorption properties of these materials in liquid-phase adsorption. With respect to this, the adsorption of lead and cadmium divalent ions was performed under varying conditions of $\mathrm{pH}$, metal ion concentration, contact time, adsorbent dose and temperature. Morphology, texture properties, functional groups, crystallinity and thermal properties of both MOFs were examined. UiO-66 composed of sphere-like particles and covered by layers of melamine with enhancing in crystallinity and active sites as well as the total surface area increased from 1080 to $1160 \mathrm{~m}^{2} / \mathrm{g}$. The modified UiO-66 with melamine (MUiO-66) showed a notable adsorption capacity of 177.5 and $146.6 \mathrm{mg} / \mathrm{g}$ for $\mathrm{Pb}$ and $\mathrm{Cd}$ (II) ions, respectively. Adsorption of both metals fitted well with the pseudo-second-order kinetic and Langmuir models and controlled by a physisorption mechanism at $\mathrm{pH}$ of 5 . Also, adsorption process is an endothermic in nature and desorption is achieved well for three cycles by MUiO-66. Therefore, UiO-66 and MUiO-66 obtained in this work have a great promise in adsorption of heavy metals such as $\mathrm{Pb}$ and $\mathrm{Cd}(\mathrm{II})$ ions from wastewater.

\section{Introduction}

With the development of industrial and agricultural modernization, an increase in the activities of mining, electroplating, smelting, batteries industry and others is occurred and caused serious water pollution with heavy metals such as cadmium ( $\mathrm{Cd})$, copper $(\mathrm{Cu})$, lead $(\mathrm{Pb})$, arsenic $(\mathrm{As})$ and chromium $(\mathrm{Cr})$, which cause high toxicity to human and environment. Heavy metals are difficult to be degraded in water, and can cause serious threats to the survival of aquatic organisms or enter the human body through the food chain to cause health risks. For example, lead can cause many diseases related to digestive, circulatory, respiratory and other systems, and even death when it enters the human body. Also, cadmium ions can accumulate in the body and cause diseases of the lung, bone and kidney. Thus, it is essential to develop promising techniques for simultaneous removal of $\mathrm{Pb}$ (II) and $\mathrm{Cd}(\mathrm{II})$ from wastewater prior to their discharge into the environment. To date, the treatment techniques for heavy metals contaminated wastewater mainly include chemical precipitation, electrolysis, ion exchange, biological treatment and adsorption (1-5). The efficiency of these processes depends on its nature and the contaminated pollutants. Among these methods, the adsorption process is the more acceptable to apply for their simplicity and low cost $(1,2)$. The most familiar adsorbent materials are activated carbons, carbon nanoparticles, zeolite, clays, fly ash and some metal oxides (6-9). Often these adsorbents materials need pretreatments to increase their removal efficiency. During the last three decades, the works directed to the synthetic adsorbents with high surface area and environmentally friendly such as metal-organic frameworks (MOFs).

Metal-organic frameworks (MOFs) are novel class of porous crystalline materials composed of two fragments, i.e. inorganic cations and organic linkers (10). Such materials have quickly moved to the forefront of materials research due to their extraordinary internal surface areas and porosity, chemical stability, and surface capability to selectively capture of guest species (10-19). Accordingly, MOFs can be 
used in many applications such as gas storage, separation, catalysis, sensing, drug delivery, biological and proton conduction.

Recently, MOFs have attracted great interest with respect to the capture of hazardous pollutants which existed in wastewater $(10,11)$. These materials are recognized to be considerably superior adsorbents as compared to conventional materials such as activated carbons and zeolites (14). Among various MOFs, UiO-MOF formulations (UiO-66, UiO-67, UiO-68, and UiO-69) have superior stability in different chemical media with large porosity $(11,16-21)$. Thus they can be emerged as effectively adsorbents for removal of heavy metal ions from a variety of wastewater samples $(11,16)$. It was found that the maximum adsorption capacity of melamine-UiO-66 prepared hydrothermally at $120^{\circ} \mathrm{C}$ toward $\mathrm{Pb}$ (II) was $122 \mathrm{mg} / \mathrm{g}$ (16). However in another study, $\mathrm{NH}_{2}$-functionalized Zr-MOFs sample prepared via rapid microwave were examined for removal of $\mathrm{Pb}$ and $\mathrm{Cd}$ (II) ions. The adsorption capacity was reached to $166.7 \mathrm{mg} / \mathrm{g}$ of $\mathrm{Pb}$ (II) and $177.3 \mathrm{mg} / \mathrm{g}$ of $\mathrm{Cd}(\mathrm{II})$ ions (21).

In a recent paper by Hanna et al. (22), Cu-MOF and Cu-MOF modified with melamine were prepared and used as antimicrobial agents. The results showed that both MOF samples exhibited a high antimicrobial activity and the incorporation of melamine to Cu-MOF increased this activity. Objective of the current study is to prepare MOF samples of UiO-66 hydrothermally at $140^{\circ} \mathrm{C}$ for $36 \mathrm{~h}$ and then UiO-66 was modified with melamine (MUiO-66); not like conditions reported by Yin et al. (16) at $120^{\circ} \mathrm{C}$ for $24 \mathrm{~h}$. The adsorption experiments of $\mathrm{Pb}$ (II) and $\mathrm{Cd}$ (II) from their aqueous solutions were conducted using the obtained MOF materials. With regard to this, the adsorption of both metal divalent ions was performed under varying conditions of $\mathrm{pH}$, metal ion concentration, contact time, adsorbent dose and temperature. Equilibrium adsorption studies were analyzed using Lagergren's pseudo first-order and pseudo secondorder models as well as Langmuir, Freundlich, and Dubinin-Radushkevich (D-R) and Redlich-Peterson isotherms were applied to identify the adsorption behavior of $\mathrm{Pb}$ and $\mathrm{Cd}$ (II) ions by UiO-66 and MUiO-66 adsorbents.

\section{Experimental}

\subsection{Materials}

Anhydrous $\mathrm{N}, \mathrm{N}$-dimethylformamide (DMF, 99\%), terephthalic acid $\left(\mathrm{H}_{2} \mathrm{BDC}, 98 \%\right)$, melamine, ethanol and zirconium tetrachloride $\left(\mathrm{ZrCl}_{4}\right)$ were obtained from Sigma Aldrich.

\subsection{Synthesis of Ui0-66}

Synthesis of UiO- 66 was carried out by hydrothermal method through dissolving $0.480 \mathrm{~g}$ of Zirconium tetraclorid $\left(\mathrm{ZrCl}_{4}\right)$ and $(3.66 \mathrm{~g})$ terephthalic acid $\left(\mathrm{H}_{2} \mathrm{BDC}\right)$ in $45 \mathrm{~mL} \mathrm{~N}, \mathrm{~N}$-Dimethylformamide (DMF), and then stirred with magnetic stirrer for 60 minutes. The reaction mixture was then heated in an oven at $140^{\circ} \mathrm{C}$ for $36 \mathrm{~h}$. The reaction mixture was removed from the oven and allowed to cool at room temperature. The solvent was then removed from the vial bottles by decantation, the solid was washed by 
adding $45 \mathrm{~mL}$ of DMF and left for 24 hours. The washing process was repeated twice with chloroform as the solvent. The obtained solid was then dried under vacuum at $60^{\circ} \mathrm{C}$.

\subsection{Synthesis of melamine-coated UiO-66 (MUiO-66)}

About $0.5 \mathrm{~g}$ of UiO-66 and $1.0 \mathrm{~g}$ of melamine (M) were dispersed in $50 \mathrm{~mL}$ and $100 \mathrm{~mL}$ absolute ethanol, respectively. The two dispersions were mixed and sonicated for $10 \mathrm{~h}$ before the mixture was transferred to a flask. When the condensation reflux reaction had lasted for $24 \mathrm{~h}$ at $100^{\circ} \mathrm{C}$, the product was centrifugally rinsed with absolute ethanol and vacuum desiccation at $50^{\circ} \mathrm{C}$ overnight to obtain melaminecoated UiO-66 (MUiO-66).

\subsection{Characterization Techniques}

The dried samples were exposed to different techniques as follows.

Transmission Electron Microscope (TEM) to identify the morphology and the particle size of the prepared samples was examined by using a transmission electron microscope (TEM) quanta FEG working at 100 $\mathrm{keV}$.

BET surface area measurements were performed at liquid nitrogen temperature $\left(-196^{\circ} \mathrm{C}\right)$ with an Autosorb BET apparatus from Quanta chrome Corporation. The BET analysis procedure is automated and operates with the static volumetric technique. Before each measurement, the samples were degassed firstly at $200^{\circ} \mathrm{C}$ for 2 hours, at $5 \times 10^{-3}$ torr and then at room temperature for 2 hours, at $0.75 \times 10^{-6}$ torr. The isotherm methods were used to determine the specific surface areas using the BET equation.

Fourier transforms infrared (FTIR) spectroscopy to give the main functional groups on the obtained samples was done using a $\mathrm{KBr}$ disk technique and FTIR 6500 spectrometer (JASCO, Japan) in the range of $400-4000 \mathrm{~cm}^{-1}$.

X-ray diffraction (XRD) analysis to determine the main crystalline was performed with power D8 ADVANCE diffractometer (Germany) using CuKa radiation $\left(1.542^{\circ} \mathrm{A}, 40 \mathrm{KV}, 40 \mathrm{~mA}\right)$ in the $2 \theta$ range of $4-$ 80. The acquisition parameters were as: a step size of 0.02 and a step time of $0.4 \mathrm{~s}$.

Thermal analysis (TGA) was performed by USA Berkin - Elmer thermo-gravimeter. Samples of approximately $10 \mathrm{mg}$ were heated from $50^{\circ} \mathrm{C}$ to $800^{\circ} \mathrm{C}$ with heating rate $10 / \mathrm{m}$ under a nitrogen atmosphere, and the flow of nitrogen was $50 \mathrm{~mL} / \mathrm{min}$.

\subsection{Adsorption studies}

The adsorption behavior of the prepared MOFs for metal ions of $\mathrm{Pb}$ (II) and $\mathrm{Cd}$ (II) was investigated by batch removal experiments at room temperature (298K). Stock solutions of the metal ions were prepared using $\mathrm{Pb}\left(\mathrm{NO}_{3}\right)_{2} \cdot 6 \mathrm{H}_{2} \mathrm{O}$ and $\mathrm{CdCl}_{2}$ salts dissolved in deionized water. Freshly prepared working metals solutions of concentrations $10 \mathrm{mg} /$ I by diluting stock solutions with deionized water were used in the experiments. The samples were collected at different time intervals and filtered with a $0.45 \mu \mathrm{m}$ syringe 
filter membrane. The $\mathrm{pH}$ effect on the adsorption was studied by adjusting the solution $\mathrm{pH}$ with sodium hydroxide $(\mathrm{NaOH})$ and nitric acid $\left(\mathrm{HNO}_{3}\right)$. The effect of adsorbent dose was studied by changing the dose from $0.05-2 \mathrm{~g} / \mathrm{L}$. All adsorption tests were performed in triplicate.

The removal efficiency and the adsorbed amount were calculated using the following equations:

$$
\text { MetalsRemoval }(\%)=\frac{C o-C e}{C o} \times 100
$$

1

The experimental data obtained in batch studies were used to calculate the adsorption capacity $\mathrm{q}_{\mathrm{e}}$ $(\mathrm{mg} / \mathrm{g})$ at equilibrium using the following equation,

$$
q_{e=}\left(C \circ-C_{e}\right) \frac{V}{m}
$$

2

Where $\mathrm{C}_{0}$ and $\mathrm{C}_{\mathrm{e}}$ are the initial and equilibrium concentrations $(\mathrm{mg} / \mathrm{L})$ of the metal solutions, respectively. $\mathrm{V}(\mathrm{L})$ is volume of metal solution and $\mathrm{m}(\mathrm{g})$ is the total mass of the used adsorbent.

To investigate the adsorption performance, adsorption isotherms for the individual adsorption of ( $\mathrm{Pb}$ (II), and $\mathrm{Cd}(\mathrm{II})$ ) were studied by contacting the optimum dose of adsorbent with different metals solutions at different initial concentration (25-250 mg/L).

The data of isotherms were analyzed, fitted and plotted using Origin Pro 2016 Ver. 9.3.226 for different non-linear regression models as shown in Table 1.

Table 1

Texture properties of UiO-66 and MUiO-66

\begin{tabular}{|lll|}
\hline Materials & BET Surface area $\left(\mathbf{m}^{2} \mathbf{g}^{-1}\right)$ & Pore volume $\left(\mathrm{cm}^{3} \mathbf{g}^{-1}\right)$ \\
\hline UiO-66 & 1080 & 0.58 \\
\hline MUiO-66 & 1160 & 0.70 \\
\hline
\end{tabular}

The mechanism of adsorption was studied by applying kinetic models using the optimized dose and $\mathrm{pH}$ for different time intervals $(5,10,15,20,25,30,40,60,90,120,150 \mathrm{~min})$ and the used kinetic models are shown in Table 1.

Thermodynamic studies are important to determine the feasibility and spontaneity of the adsorption process. Thermodynamic parameters as Gibbs free energy $\left(\Delta \mathrm{G}^{\circ}\right)$, the enthalpy change $\left(\Delta \mathrm{H}^{\circ}\right)$ and entropy change $\left(\Delta \mathrm{S}^{\circ}\right)$ were obtained by applying the adsorption of $\mathrm{Pb}(\mathrm{II})$ and $\mathrm{Cd}(\mathrm{II})$ ions at different temperatures ( $\mathrm{T}=313,333$ and $353 \mathrm{~K}$ ) and the experimental data obtained were fitted by the following equations: 


$$
\Delta \mathrm{G}^{\circ}=-\mathrm{RT} \ln K_{d}
$$

$$
\mathrm{K}_{\mathrm{d}}=\frac{\Delta \mathrm{S}}{\mathrm{R}}-\frac{\Delta \mathrm{H}}{\mathrm{RT}}
$$

4

Where, $\mathrm{K}_{\mathrm{d}}$ is the distribution coefficient of the solute which is equal $\mathrm{q}_{\mathrm{e}} / \mathrm{C}_{\mathrm{e}}$, and $\mathrm{R}$ is the ideal gas constant $(8.314 \mathrm{~J} / \mathrm{mol} \mathrm{K})$.

\subsection{Desorption studies of metal ions}

Desorption studies were done to estimate and reusability of adsorbents and leaching studies of metalloaded MOF samples under initial concentration of metal ions $10 \mathrm{mg} / \mathrm{L}$ and room temperature. After adsorption experiments, metal ions were eluted using $\mathrm{HNO}_{3} 0.1 \mathrm{M}$. After desorption, the MOF sample was separated by filtration and metals concentrations were measured then the adsorbent was rinsed with deionized water till the $\mathrm{pH}$ was neutral then dried and reconditioned for reuse in another run.

\section{Results And Discussion}

\subsection{General features of Ui0-66 and MUiO-66}

Figure 1 represents the TEM image of UiO-66 and MUiO-66. It can be concluded that the UiO- 66 particles were formed from aggregated spheres-like with particle sizes ranged between 20-60 nm as shown in Fig. 1A. This result is consistent with previous study on UiO-66 (16). Upon modification of UiO-66 with melamine, TEM image of MUiO-66 (Fig. 1B) shows covering the surface of UiO-66 with layers from melamine molecules. This treatment enhanced the porous properties and crystallinity of UiO-66 as shown in BET and XRD measurements.

Table 1 lists the BET surface area measurements of the parent UiO-66 and one coated with melamine (MUiO-66). Results explain that the total surface area of UiO-66 equals to $1080 \mathrm{~m}^{2} / \mathrm{g}$ and total pore volume $0.58 \mathrm{~cm}^{3} / \mathrm{g}$ while the MUiO-66 has a larger total surface area about $1160 \mathrm{~m}^{2} / \mathrm{g}$ and total pore volume $0.70 \mathrm{~cm}^{3} / \mathrm{g}$. This indicates that both the surface area and pore volume improved by introducing the melamine molecules into the surface of UiO-66. Yin et al. (16) prepared UiO-66 and melamine-UiO-66 during the hydrothermal route at $120^{\circ} \mathrm{C}$ for $24 \mathrm{~h}$ and found that the total surface areas of both products were 303 and $371 \mathrm{~m}^{2} / \mathrm{g}$, respectively, which are lesser than those obtained in this study. On the other hand, Shearer et al. (18) synthesized UiO-66 functionalized with L-Serine and monoethanol amine and activated with $\mathrm{HCl}$ having BET-surface areas ranged from 1372 to $1903 \mathrm{~m}^{2} / \mathrm{g}$. By the way, the higher total surface area and total pore volume is the larger adsorption capacity and thus MOFs of UiO-66 can candidate to use in the removal of heavy metals from aqueous solutions. 
As shown in Fig. 2, FTIR spectra of UiO-66 and MUiO-66 samples are measured. Regarding UiO-66 (Zr), the strong bands belonging to the $\mathrm{O}-\mathrm{C}-\mathrm{O}$ asymmetric and symmetric stretching in the $\mathrm{H}_{2} \mathrm{BDC}$ ligand can be found at 1600 and $1419 \mathrm{~cm}^{-1}$. The weak band at $1510 \mathrm{~cm}^{-1}$ demonstrates the vibration $\mathrm{C}=\mathrm{C}$ of a benzene ring. The peaks at 808,746 , and $658 \mathrm{~cm}^{-1}$ are combined with $\mathrm{C}-\mathrm{H}$ vibration, $\mathrm{C}=\mathrm{C}$ stretch, $\mathrm{OH}$ bend and $\mathrm{O}-\mathrm{C}-\mathrm{O}$ bend in the $\mathrm{H}_{2} \mathrm{BDC}$ ligand. In addition, a band related to the $\mathrm{C}=0$ asymmetric stretch of the DMF can be demonstrated at $1655 \mathrm{~cm}^{-1}$, which means that DMF resides in the pores. However, no absorption band was observed in $1685 \mathrm{~cm}^{-1}$, which is related to the carboxylate vibration bands of the free $\mathrm{H}_{2} \mathrm{BDC}$ ligand, indicating that all carboxylates are connected to zirconium ( $\mathrm{Zr}$ ) ions (18). The absorption bands of FTIR at 3121, 3324, 3415 and $3467 \mathrm{~cm}^{-1}\left(\mathrm{NH}_{2}\right.$ stretching), as well as $1651 \mathrm{~cm}^{-1}$ $(\mathrm{C}=0$ stretching), which are attributable to primary amine group of melamine, have disappeared or drastically reduced upon reaction of the MOFs with melamine in the synthesis of melamine-MOFs $[16,18$, 20]. In addition, the structures of the triazine ring give the strong stretching vibration bands at $1465 \mathrm{~cm}^{-1}$ ( $C=N$ vibration), mirroring the successful incorporation of the melamine into the framework $(16,20)$. The amino groups $\left(-\mathrm{NH}_{2}\right)$ have lone pair electrons and act as the Lewis base, they can form coordinate bonds with the heavy metal ions (Lewis acids) (21).

The XRD patterns of the unmodified and modified MOFs (Fig. 3) were very similar, confirming the successful synthesis and the integrity of the crystal structure after modification with melamine. The melamine-UiO-66 MOF exhibited higher peak intensities at about $2 \theta=7.4^{\circ}, 8.5^{\circ}, 15^{\circ}$ and $15.8^{\circ}$ showing an increase in the crystalline degree of the UiO-66. Moreover, the two diffraction peaks of the melamine $(2 \theta=$ $26^{\circ}$ and $30^{\circ}$ ) were seen in the XRD patterns of the melamine-MOFs $(16,18)$. Thus, there might be mainly chemical interaction between melamine and the MOFs during the prescribed method.

Figure 4 represents the thermo-gravimetric analysis (TGA) of the UiO-66 and melamine/UiO-66 (MuiO-66). From this Ui0-66 it is observed that the thermal degradation of the sample passes through at three progressive steps. The first one starts from the room temperature and ends nearly at $150^{\circ} \mathrm{C}$ can be attributed to evaporate the water content and the other volatile materials. The second step starts gradually until to $200^{\circ} \mathrm{C}$ and then the degradation become rapidly until $350^{\circ} \mathrm{C}$, and this step represents the main degradation of the UiO- 66 . The third steps starts at $350^{\circ} \mathrm{C}$ and continue in the degradation to the $800^{\circ} \mathrm{C}$. This stage may due to the decomposition of the inorganic fragments. For MUiO-66, it is observed that there are similarities with that observed for the sample without melamine. In comparison between the two profiles it is observed that the thermal degradation of the main product goes gradually between about $200^{\circ} \mathrm{C}$ to $350^{\circ} \mathrm{C}$ and continues. This may be due to the presence of the melamine as confirmed by previous work $(16,18)$.

\subsection{Factors affecting adsorption studies}

\section{2.i Effect of $\mathrm{pH}$}


Figure 5 shows the variation of \% removal of both heavy metals using two MOF samples with increasing $\mathrm{pH}$ of solution from 2 to 7 . The highest removal of $\mathrm{Pb}(\mathrm{II})$ and $\mathrm{Cd}$ (II) ions is occurred at $\mathrm{pH}$ of 5 .

Increasing $\mathrm{pH}$ over 5 , the \% removal of both metals decreases slightly as result of presence of $\mathrm{Pb}(\mathrm{OH})_{2}$ or $\mathrm{Cd}(\mathrm{OH})_{2}$ in the solution. It can be seen that MUiO-66 exhibits a high removal of $\mathrm{Pb}$ and $\mathrm{Cd}(\mathrm{II})$ ions $(>75 \%$ removal) within studied $\mathrm{pH}$ range between 2 and 7. This confirms the superiority of MUiO-66 adsorbent to work at different media of $\mathrm{pH}$.

\section{2. ii Effect of initial concentrations and contact time}

Figure 6 illustrates the removal percentage of both $\mathrm{Pb}$ and $\mathrm{Cd}$ ions by UiO-66 and MUiO-66 samples as function of variation in contact time and initial concentrations of metal ions studied here. When initial concentrations of metal ions increase from 5 to $100 \mathrm{mg} / \mathrm{L}$ the removal percentage of $\mathrm{Pb}$ and $\mathrm{Cd}$ divalent ions is decreased gradually by both samples. MUi0-66 sample exhibits superior removal toward both metal ions than by Ui0-66 sample because of it possesses high total surface area and accessible micropores in addition to presence of $-\mathrm{NH}_{2}$ groups. In addition, the removal percentage of $\mathrm{Pb}$ (II) $(91-83 \%$ at $5 \mathrm{~min}$ and $96-88 \%$ at $150 \mathrm{~min}$ ) ions is higher than that of $\mathrm{Cd}$ (II) ions (74-66\% at $5 \mathrm{~min}$ and $84-73 \%$ ) by UiO-66 as concentration increases from 5 to $100 \mathrm{mg} / \mathrm{L}$. This finding may be ascribed to that the hydrated ionic radius of cadmium ions $(0.426 \mathrm{~nm})$ is greater than that of lead ions $(0.401 \mathrm{~nm})$ when attached with water molecules $(23,24)$.

Generally, the removal of both metals ions is increased by increasing the contact time and equilibrium time is occurred almost after $50 \mathrm{~min}$ for $\mathrm{Pb}$ (II) ions and $60 \mathrm{~min}$ for $\mathrm{Cd}$ (II) ions adsorption over both MOF samples. For $\mathrm{Pb}$ (II) adsorption, the removal by two samples is very fast at early stage and then began to be slow at equilibrium that is owing to the saturation of the available adsorption sites.

\section{2. iii Effect of MOF dosage}

Figure 7 depicts the effect of UiO-66 and MUiO-66 samples on the adsorption of $\mathrm{Pb}$ and $\mathrm{Cd}$ (II) ions at $\mathrm{pH}$ 5 and $25^{\circ} \mathrm{C}$. As MOF dosage increases from 0.05 to $1 \mathrm{~g} / \mathrm{L}$, the removal of each metal ion increases gradually and then starts to decrease slightly at $1.5 \mathrm{~g} / \mathrm{L}$, resulting in the high availability of binding sites on the surface at a higher adsorbent dose. Thus, a $1 \mathrm{~g} / \mathrm{L}$ adsorbent was selected as adsorbent dosage for all further experiments due to its higher removal efficiency.

Based on the high removal efficiency of lead and cadmium by MUiO-66 sample under varying variables such as $\mathrm{pH}$, initial concentration, contact time and adsorbent dosage, this sample was used to estimate the kinetic and equilibrium adsorption of $\mathrm{Pb}$ and $\mathrm{Cd}$ (II) ions using different models as summarized in Table 2. 
Table 2

Kinetics and isothermal models (Non-linear form)

Non-linear form

$q_{t}=q_{e}-\left(1-\mathrm{e}^{\left(-\mathrm{K}_{1} t\right)}\right)$

Pseudo-first order

Kinetics models

Pseudo-second order

$$
q_{t}=\frac{K_{2} q_{e}^{2} t}{1+k_{2} q_{e} t}
$$$$
q_{e}=K_{F} C_{e}^{1 / n}
$$

Isotherm models

Freundlich model

Langmuir model

$$
q_{e}=q_{m} K_{L} \frac{C_{e}}{1+K_{L} C_{e}}
$$

Dubinin-

Radushkevich (DR) model

$$
\begin{aligned}
& \mathrm{q}_{\mathrm{e}}=q_{\mathrm{D}-\mathrm{R}} e\left[-k_{D-R}\left(\mathrm{RT} \ln \left(1+\frac{1}{\mathrm{C}_{\mathrm{e}}}\right)\right)^{2}\right] \\
& \mathrm{E}=\frac{1}{\sqrt{-2 \beta}}
\end{aligned}
$$

\section{Parameter}

$\mathbf{k}_{1}(1 / \mathrm{min})$ is the pseudo-firstorder rate constant

$\mathbf{k}_{\mathbf{2}}(\mathrm{mg} / \mathrm{g} \mathrm{min})$ is the pseudosecond-order rate constant

$\mathbf{k}_{\mathrm{F}}(\mathrm{L} / \mathrm{g})$ Freundlich constant related to adsorption capacity,

n Freundlich constant related to adsorption intensity.

$\mathrm{q}_{\mathrm{m}}(\mathrm{mg} / \mathrm{g})$ maximum monolayer adsorption capacity,

$\mathbf{k}_{\mathrm{L}}$ (L/mg) Langmuir equilibrium constant.

$q_{D-R}(\mathrm{mg} / \mathrm{g})$ maximum adsorption capacity

$k_{D-R}\left(\mathrm{~mol}^{2} / \mathrm{J}^{2}\right)$ constant related to the mean free energy of adsorption

$\mathbf{R}(8.314 \mathrm{~J} / \mathrm{mol} \mathrm{K})$ general gas constant

$\mathbf{T}(\mathrm{K})$ absolute temperature

$E(\mathrm{~kJ} / \mathrm{mol})$ mean free energy:

$\mathrm{K}_{\mathrm{RP}}(\mathrm{L} / \mathrm{mg})$ is $\mathrm{R}-\mathrm{P}$ constant related to the adsorption capacity,

$a_{\mathrm{RP}}(\mathrm{L} / \mathrm{mg})$ is a constant related to the affinity of the binding sites ,

$\mathbf{g}(\mathrm{g})$ is an exponent related to the adsorption intensity. 
Lagergren's pseudo first-order and pseudo second-order models were used for analysis of adsorption kinetics as shown in Table 2.

The Lagergren's first-order rate constant $\left(k_{1}\right)$ and $q_{\mathrm{e}}$ are calculated from the intercept and slope of the plot between $\mathrm{t}(\mathrm{min})$ versus $\log \left(\mathrm{q}_{\mathrm{e}}-\mathrm{q}_{\mathrm{t}}\right)$ and listed in Table 3 along with the corresponding correlation coefficients $\left(\mathrm{R}^{2}\right)$. It was observed that the pseudo first-order model did not fit well the adsorption of $\mathrm{Pb}$ and Cd (II) ions by MUiO-66 sample because the calculated $q_{\mathrm{e}}$ values do not agree with the experimental $q_{\mathrm{e}}$ values. This suggests that the adsorption of studied metal ions does not follow first-order kinetic model. On the other hand, the equilibrium sorption capacity $\left(q_{\mathrm{e}}\right)$ and the second-order constant $k_{2}(\mathrm{~g} / \mathrm{mg}$ $\mathrm{min}$ ) can be determined experimentally from the slope and intercept of plot $t / q t$ versus $t$. The values of $k_{2}$ and $q_{\mathrm{e}}$ are listed in Table 3 along with the corresponding correlation coefficients $\left(\mathrm{R}^{2}=0.99\right)$. It can be seen that there is an agreement between experimental and calculated $q_{\mathrm{e}}$ values for the pseudo secondorder model with $\mathrm{R}^{2}$ closing to unity (Table 3 ). Hence, the pseudo second-order model better represents the sorption kinetics. 
Table 3

Parameters for kinetics and isotherm models fit

\begin{tabular}{|c|c|c|c|c|}
\hline \multirow[t]{2}{*}{ Metal } & \multicolumn{4}{|c|}{ Pseudo-first order } \\
\hline & $q_{e, e x p .}(m g / g)$ & $\mathrm{q}_{\mathrm{e}, \mathrm{Cal}}(\mathrm{mg} / \mathrm{g})$ & $\mathrm{K}_{1}$ & $\mathrm{R}^{2}$ \\
\hline $\mathrm{Pb}(\mathrm{II})$ & 9.4 & 0.89 & 0.05 & 0.06 \\
\hline \multirow[t]{3}{*}{$\mathrm{Cd}(\mathrm{II})$} & 8.3 & 1.7 & 0.03 & 0.07 \\
\hline & \multicolumn{4}{|c|}{ Pseudo-second order } \\
\hline & $\mathrm{q}_{\mathrm{e}, \mathrm{Cal}}(\mathrm{mg} / \mathrm{g})$ & $\mathrm{K}_{2}(\mathrm{~g} / \mathrm{mg} \cdot \mathrm{min})$ & \multicolumn{2}{|l|}{$\mathrm{R}^{2}$} \\
\hline $\mathrm{Pb}(\mathrm{II})$ & 9.7 & 0.14 & & \\
\hline \multirow[t]{3}{*}{$\mathrm{Cd}(\mathrm{II})$} & 8.4 & 0.04 & & \\
\hline & \multicolumn{4}{|c|}{ Langmuir isotherm parameters } \\
\hline & $\mathrm{q}_{\mathrm{m}}(\mathrm{mg} / \mathrm{g})$ & \multicolumn{2}{|l|}{$\mathrm{K}_{\mathrm{L}}(\mathrm{L} / \mathrm{mg})$} & $\mathrm{R}^{2}$ \\
\hline $\mathrm{Pb}(\mathrm{II})$ & 177.5 & 0.07 & 0.99 & \\
\hline \multirow[t]{3}{*}{$\mathrm{Cd}(\mathrm{II})$} & 146.6 & 0.03 & 0.98 & \\
\hline & \multicolumn{4}{|c|}{ Freundlich isotherm parameters } \\
\hline & $1 / n$ & $\mathrm{~K}_{\mathrm{F}}(\mathrm{L} / \mathrm{mg})$ & & $\mathbf{R}^{2}$ \\
\hline $\mathrm{Pb}(\mathrm{II})$ & 0.38 & 29 & & 0.94 \\
\hline \multirow[t]{3}{*}{$\mathrm{Cd}(\mathrm{II})$} & 0.45 & 13 & & 0.95 \\
\hline & \multicolumn{4}{|c|}{ D-R isotherm parameters } \\
\hline & $\mathrm{q}_{\mathrm{K}-\mathrm{D}}(\mathrm{mg} / \mathrm{g})$ & $\mathrm{E}(\mathrm{kJ} / \mathrm{mol})$ & & $\mathrm{R}^{2}$ \\
\hline $\mathrm{Pb}(I I)$ & 144 & 11 & & 0.91 \\
\hline \multirow[t]{3}{*}{$\mathrm{Cd}(\mathrm{II})$} & 110 & 9.7 & & 0.90 \\
\hline & \multicolumn{4}{|c|}{ Redlich-Peterson parameters } \\
\hline & $\mathrm{K}_{\mathrm{R}}(\mathrm{L} / \mathrm{mg})$ & $a_{R}(L / m g)$ & $g(g)$ & $\mathrm{R}^{2}$ \\
\hline $\mathrm{Pb}(\mathrm{II})$ & 13.4 & 0.07 & 1 & 0.98 \\
\hline $\mathrm{Cd}(\mathrm{II})$ & 5.5 & 0.075 & 0.86 & 0.95 \\
\hline
\end{tabular}

Figure 8 shows the studied adsorption isotherms of $\mathrm{Pb}$ and $\mathrm{Cd}$ (II) ions onto MUiO-66. Meaning, the Langmuir, Freundlich, Dubinin-Radushkevich (D-R) and Redlich-Peterson isotherms (Table 2) were applied to identify the best model fitting the adsorption of both metal ions onto MUiO-66. Constants 
calculated from these isotherms with the corresponding values of $R^{2}$ are listed in Table 3. Values of $R^{2}$ showed that the adsorption of both metals ions fits finely the isotherms in the sequence order: Langmuir $>$ Redlich-Peterson > Freundlich> D-R. The fact that the Langmuir isotherm fits the adsorption data very well may be attributed to the homogeneous distribution of active sites on MUiO-66 sample. Maximum monolayer adsorption capacity of MUiO-66 accounted from Langmuir isotherm $\left(\mathrm{q}_{\mathrm{m}}, \mathrm{mg} / \mathrm{g}\right)$ toward adsorption of $\mathrm{Pb}$ (II) and Cd (II) ions was approximately 178 and $147 \mathrm{mg} / \mathrm{g}$, respectively. This finding pointed out the preference of lead adsorption exhibited by MUiO-66 over Cd (II) ions which may be attributed to smaller hydrated radius of $\mathrm{Pb}$ (II) ions (23). The MUiO-66 obtained in this study exhibited superb adsorption capacity as compared to that was prepared by Yin et al. [16]. Calculated mean free energy $(E, \mathrm{~kJ} / \mathrm{mol})$ from $\mathrm{DR}$ isotherm can identify the type of adsorption whether is physical or chemical. When the $E$ value ranged between $8-16 \mathrm{~kJ} / \mathrm{mol}$, the adsorption process is chemical in nature $(25,26)$. In our study, the value of $E$ is found to be less than $16 \mathrm{~kJ} / \mathrm{mol}$, and thus the adsorption of metal ions is a physisorption (25-31).

\subsection{Influence of temperature and thermodynamic studies}

The feasibility of the adsorption was analyzed by studying the changes in different thermodynamic parameters, such as $\Delta \mathrm{G}^{\circ}, \Delta \mathrm{H}^{\circ}$ and $\Delta \mathrm{S}^{\circ}$ with temperature by the Van't Hoff plot (Eq. 4). The temperature affected the adsorption, where the ion mobility of $\mathrm{Pb}$ (II) and $\mathrm{Cd}(\mathrm{II})$ ions increased with the temperature and the adsorption is enhanced due to the increased in ions number on the active sites of the MOF adsorbent. The calculated parameters for the tested metal ions are listed in Table 4. The negative values of $\Delta \mathrm{G}^{\circ}$ for $\mathrm{Pb}$ (II) and $\mathrm{Cd}(\mathrm{II})$ ions adsorption revealed that the adsorption was spontaneous. Values of $\Delta \mathrm{G}^{\circ}$ are $\otimes-20 \mathrm{~kJ} / \mathrm{mol}$ and suggested to be obtained for the physical adsorption and the interaction occurs between the metal ion and the active sites existed on MOF's surface $(25,26)$. The positive value of $\Delta \mathrm{H}^{\circ}$ (Table 4) for $\mathrm{Pb}(\mathrm{II})$ and $\mathrm{Cd}(\mathrm{II})$ adsorption, suggested that the adsorption was endothermic process. The positive value of $\Delta S^{\circ}$ reveals the randomness between the solid and liquid surface confirming the high affinity between the adsorbent and metal ions (25). 
Table 4

Thermodynamic parameters for the adsorption of $\mathrm{Pb}$ (II) and $\mathrm{Cd}$ (II) ions at different temperatures.

\begin{tabular}{|lllll|}
\hline Metal & $\begin{array}{l}\text { Temperature } \\
(\mathrm{K})\end{array}$ & $\Delta \mathrm{G}(\mathrm{kJ} / \mathrm{mol}))$ & $\Delta \mathrm{H}(\mathrm{kJ} / \mathrm{mol})$ & $\Delta \mathrm{S}(\mathrm{J} / \mathrm{mol} \mathrm{K})$ \\
\hline $\mathrm{Pb}(\mathrm{II})$ & 313 & -7.6 & 21.4 & 92.2 \\
& 333 & -8.7 & & \\
& 353 & -11.4 & & \\
$\mathrm{Cd}(\mathrm{II})$ & 313 & -4.5 & 16.4 & \\
& 333 & -6.4 & & \\
& 353 & -7.2 & & \\
\hline
\end{tabular}

\subsection{Desorption studies}

The reusability experiments of metal loaded adsorbents were carried out and results are shown in Fig. 9. An increase in desorption for $\mathrm{Pb}(\mathrm{II})$ and $\mathrm{Cd}(\mathrm{II})$ at low $\mathrm{pH}$ values was observed. By applying adsorption/ desorption cycles, a small loss (8\%) in the adsorption efficiency for the prepared MUiO-66 starting from the third cycle, revealing the good reusability of the prepared adsorbent.

Table 5 lists the adsorption capacities of some adsorbents used in removal of lead and cadmium ions. Results in the table affirms the highest performance of MOFs toward removal of lead and cadmium ions, excepting the natural zeolite which exhibited a superior capacity toward $\mathrm{Pb}$ (II) and a lower adsorption of $\mathrm{Cd}$ (II) as compared to MUiO-66 prepared in this study. 
Table 5

Adsorption capacities of various adsorbents for adsorption of $\mathrm{Pb}$ and $\mathrm{Cd}$ (II) ions.

\begin{tabular}{|llll|}
\hline \multirow{2}{*}{ Adsorbents } & \multicolumn{2}{l}{ Adsorption Capacity (mg/g) } & Ref. \\
\cline { 2 - 3 } & $\mathrm{Pb}(\mathrm{II})$ & $\mathrm{Cd}(\mathrm{II})$ & \\
\hline HCl-treated Egyptian Kaolin & 34.5 & - & {$[6]$} \\
\hline UiO-66 & 72 & - & {$[16]$} \\
Melamine-UiO-66 & 122 & - & \\
\hline UiO-66 MOFs & $110-175$ & - & {$[17]$} \\
\hline $\mathrm{NH} 2$ functionalized Zr-MOFs & 166.7 & 177.3 & {$[21]$} \\
\hline semi-carbonized/H ${ }_{3} \mathrm{PO}_{4}$ cotton stalks & - & 31.6 & {$[23]$} \\
\hline KOH-activated carbons & 50 & - & {$[27]$} \\
\hline $\mathrm{H}_{3} \mathrm{PO}{ }_{4}$-Activated carbons & - & 83.4 & {$[28]$} \\
\hline biosilica extracted from marine diatom & 120.4 & - & {$[29]$} \\
\hline Amino-MIL-101 (Cr) & 81.1 & - & {$[30]$} \\
\hline Zeolite & 286 & 44.6 & {$[31]$} \\
\hline MUiO-66 & 177.5 & 146.7 & This study \\
\hline
\end{tabular}

\section{Conclusions}

From the analysis of the results, it may conclude that Ui0-66 composed of sphere-like particles and covered by layers of melamine with enhanced in crystallinity and active surface sites as a result of an incorporation of the melamine. The incorporation of melamine into the UiO-66 increased the surface area from 1080 to $1160 \mathrm{~m}^{2} / \mathrm{g}$. The maximum adsorption capacity was found 177.5 and $146.6 \mathrm{mg} / \mathrm{g}$ at $\mathrm{pH}=$ 5.0 for $\mathrm{Pb}(\mathrm{II})$ and for $\mathrm{Cd}(\mathrm{II})$, respectively. A better fit of the adsorption results was achieved using Langmuir isotherm with physisorption of both metals ions onto the studied MUiO-66. Pseudo-second order kinetic model had the best fit for the obtained experimental data, indicating that the rate limiting step is chemisorption. The adsorbed metal ions were then desorbed and the prepared MUiO- 66 was reused efficiently for other cycles of adsorption. Also, the results show that both UiO-66 and MUiO-66 have high adsorption efficiency as compared with examples of the adsorbent materials in literature.

\section{Declarations}

Acknowledgements 
The authors submit their acknowledgment to their institute (National Research Centre, Cairo, Egypt) for encouragement the team work to do this work.

\section{References}

1. X. Li, Y. Qin, Y. Jia, Y. Li, Y. Zhao, Y. Pan, J. Sun., (2021). Preparation and application of Fe/biochar (Fe-BC) catalysts in wastewater treatment: a review, Chemosphere, 274, 129766, https://doi.org/10.1016/j.chemosphere.2021.129766.

2. D. Vilela, J. Parmar, Y. Zeng., (2016). Graphene-based microbots for toxic heavy metal removal and recovery from water, Nano Letters, 16, 2860-2866, https://doi.org/10.1021/acs.nanolett.6b00768.

3. F. Dixit, R. Dutta, B. Barbeau, P. Berube, M. Mohseni., (2021). PFAS removal by ion exchange resins: a review. Chemosphere 272, 129777, https://doi.org/10.1016/j. chemosphere.2021.129777.

4. J. Kazmierczak-Razna, A. Zioła-Frankowska, P. Nowicki, M. Frankowski, R. Wolski, R. Pietrzak., (2021). Removal of heavy metal ions from One- and two-component solutions via adsorption on Ndoped activated carbon, Materials 14, 7045, https://doi.org/ 10.3390/ma14227045.

5. K. Khulbe, T. Matsuura., (2018). Removal of heavy metals and pollutants by membrane adsorption techniques, Applied Water Science, 8, 661-668, https://doi.org/10.1007/s13201-018.

6. S. Drweesh, N. Fathy, M. Wahba, A. Hanna, A. Akarish, E. Elzahany, I. El-Sherif, K. Abou-El-Sherbini., (2016). Equilibrium, kinetic and thermodynamic studies of $\mathrm{Pb}$ (II) adsorption from aqueous solutions on HCl-treated Egyptian Kaolin, Journal of Environmental Chemical Engineering, 4, 1674-16846.

7. M. Uddin., (2017). A review on the adsorption of heavy metals by clay minerals, with special focus on the past decade, Chemical Engineering Joournal, 308, 438-462, https://doi.org/10.1016/j.cej.2016.09.029.

8. N. Ammar, N. Fathy, H. Ibrahim, S. Mousa., (2021). Micro-mesoporous modified activated carbon from corn husks for removal of hexavalent chromium ions, Applied Water Science, 11, 154: 1-12, https://doi.org/10.1007/s13201-021-01487-1.

9. O. El-Shafey, Sh. El-Shafey, N. Fathy., (2022). Mesoporous carbon xerogels adsorbents for adsorption of cadmium and p-nitrophenol pollutants: kinetic and equilibrium studies, Egyptian Journal of Chemistry, 65, 487 - 497, https://dx.doi.org/10.21608/ejchem.2021.89014.4274.

10. P. Kumar, A. Pournara, K.-H. Kim,V. Bansal, S. Rapti, M. J. Manos., (2017). Metal-organic frameworks: Challenges and opportunities for ion-exchange/sorption applications, Progress in Material Science, 86, 25-74, https://doi.org/10.1016/j.pmatsci.2017.01.002.

11. J. Ru, X. Wang, F. Wang, X. Cui, X. Du, X. Lu., (2021). UiO series of metal-organic frameworks composites as advanced sorbents for the removal of heavy metal ions: Synthesis, applications and adsorption mechanism, Ecotoxicology and Environmental Safety, 208, 111577, https://doi.org/10.1016/j.ecoenv.2020.111577.

12. L. Rani, J. Kaushal, A.L. Srivastav, P. Mahajan., (2020). A critical review on recent developments in MOF adsorbents for the elimination of toxic heavy metals from aqueous solutions, Environmental 
Science Pollution Research, 27 ,44771-44796, https://doi.org/10.1007/s11356-020-10738-8.

13. D. Sun, L. Peng, W. Reeder, S. Moosavi, D. Tiana, D. Britt, E. Oveisi, W. Queen., (2018). Rapid, selective heavy metal removal from water by a metal-organic framework/polydopamine composite, ACS Central Science, 4, 349-356, https://doi.org/10.1021/acscentsci.7b00605.

14. Y. Chen, X. Bai, Z. Fang, Recent progress in heavy metal ion decontamination based on metalorganic frameworks, Nanomaterials 10 (2020), 1481; https://doi.org/10.3390/nano10081481.

15. Y. Peng, H. Huang, Y. Zhang, C. Kang, S. Chen, L. Song, D. Liu, C. Zhong.,(2018). A versatile MOFbased trap for heavy metal ion capture and dispersion, Nature Communications, 9, 187, https://doi.org/1038/s41467-017-02600-2.

16. N. Yin, K. Wang, Y. Xia, Z. Li.,(2018). Novel melamine modified metal-organic frameworks for remarkably high removal of heavy metal $\mathrm{Pb}$ (II), Desalination, 430, 120-127, http://dx.doi.org/10.1016/j.desal.2017.12.057.

17. Sh. Ali, Z. Zuhra, Y. Abbas, Y. Shu, M. Ahmad, Z. Wang, Tailoring Defect Density in UiO-66 Frameworks for Enhanced Pb(II) Adsorption, Langmuir 37 (2021) , 13602-13609. https://doi.org/10.1021/acs.langmuir.1c02032.

18. G. Shearer, J.G. Vitillo, S. Bordiga S. Svelle, U. Olsbye, K. P. Lillerud, Functionalizing the defects: Postsynthetic ligand exchange in the metal organic framework UiO-66, Chem. Mater. 28 (2016), 7190-7193.

19. H. Saleem, U. Rafique, R.P. Davies.,(2016). Investigations on post-synthetically modified UiO-66- $\mathrm{NH}_{2}$ for the adsorptive removal of heavy metal ions from aqueous solution, Microporous and Mesoporous Materials, 221, 238-244, http://dx.doi.org/10.1016\%2Fj.micromeso.2015.09.043.

20. N. Sahiner, S. Demirci, K. Sel.,(2016). Covalent organic framework based on melamine anddibromoalkanes for versatile use, Journal of Porous Materials, 23, 1025-1035, https://doi.org/10.1007/s10934-016-0160-9.

21. K. Wang, J. Gu, N. Yin., (2017). Efficient removal of $\mathrm{Pb}$ (II) and $\mathrm{Cd}$ (II) using $\mathrm{NH}_{2}$-functionalized $\mathrm{Zr}$ MOFs via rapid microwave-promoted synthesis, Industrial Engineering Chemistry Research, 56, 1880-1887 https://www.cheric.org/research/tech/periodicals/doi.php?art_seq=1534198.

22. A.S. Abdelmoaty, A.A. El-Beih, A.A. Hanna., (2022). Synthesis, characterization and antimicrobial activity of Copper-metal organic framework (Cu-MOF) and its modification by melamine, Journal of Inorganic and Organomettalic Polymer Materials, https://doi.org/ 110.21203/rs.3.rs-1069732/v1..

23. I. El-Sherif , N. Fathy., (2011). Equilibrium and kinetic study of $\mathrm{Cd}$ (II) and $\mathrm{Ni}$ (II) ions removal by semi-carbonized $/ \mathrm{H}_{3} \mathrm{PO}_{4}$ cotton stalks, Carbon Letters, 10, 2744-2758, http://dx.doi.org/10.5714/CL.2011.12.1.001.

24. I. Mobasherpour, E. Salahi, M.Pazouki, Comparative of the removal of $\mathrm{Pb}^{2+}, \mathrm{Cd}^{2+}$ and $\mathrm{Ni}^{2+}$ by nano crystallite hydroxyapatite from aqueous solutions: Adsorption isotherm study, Arabian J. Chem. 5 (2012), 439-446. 
25. Z. Yao, J. Qi, L. Wang., (2010). Equilibrium, kinetic and thermodynamic studies on the biosorption of $\mathrm{Cu}(\mathrm{II})$ onto chestnut shell, J. Hazard Materials, 174, 137-143, https://doi.org/10.1016/j.jhazmat.2009.09.027.

26. N. Samadi, R. Hasanzadeh, M. Rasad., (2015). Adsorption isotherms, kinetic, and desorption studies on removal of toxic metal ions from aqueous solutions by polymeric adsorbent, Journal of Applied Polymer Science, 132, http://dx.doi.org/ 10.1002/APP.41642.

27. N. Fathy, I. El-Sherif., (2011). Equilibrium removal of $\mathrm{Pb}$ (II) ions from aqueous solution onto oxidizedKOH-activated carbons, Carbon Letters 12, 1-7, http://dx.doi.org/10.5714/CL.2011.12.1.001.

28. M. Abdelnaeim, I. El Sherif, A. Attia, N. Fathy, M. El Shahat.,(2016). Impact of chemical activation on the adsorption performance of common reed towards $\mathrm{Cu}(\mathrm{II})$ and $\mathrm{Cd}(\mathrm{II})$, International Journal of Mineral Processing, 157, 80-88, http://dx.doi.org/10.1016\%2Fj.minpro.2016.09.013.

29. Y. Qi, J. Wang, X. Wang, J, J. Cheng, Z. Wen.,(2017). Selective adsorption of Pb (II) from aqueous solution using porous biosilica extracted from marine diatom biomass: properties and mechanism, Applied Surface Science, 396, 965-977, http://dx.doi.org/10.1016\%2Fj.apsusc.2016.11.069.

30. X. Luo, L. Ding, J. Luo., (2015). Adsorptive removal of Pb (II) ions from aqueous samples with amino-functionalization of metal-organic frameworks MIL-101 (Cr), Journal of Chemical Engineering Data, 60, 1732-1743, https://doi.org/10.1021/je501115m.

31. G. Kumara, K. Kawamoto., (2021). Use of natural zeolite and its mixtures to refine high-concentrated heavy metal-contaminated wastewater: an investigation of simultaneous removal of $\mathrm{Cd}$ (II) and $\mathrm{Pb}$ (II) by batch method, Water Air Soil Pollution. 232, 463, https://doi.org/10.1007/s11270-021-05420-9.

\section{Figures}

(A)

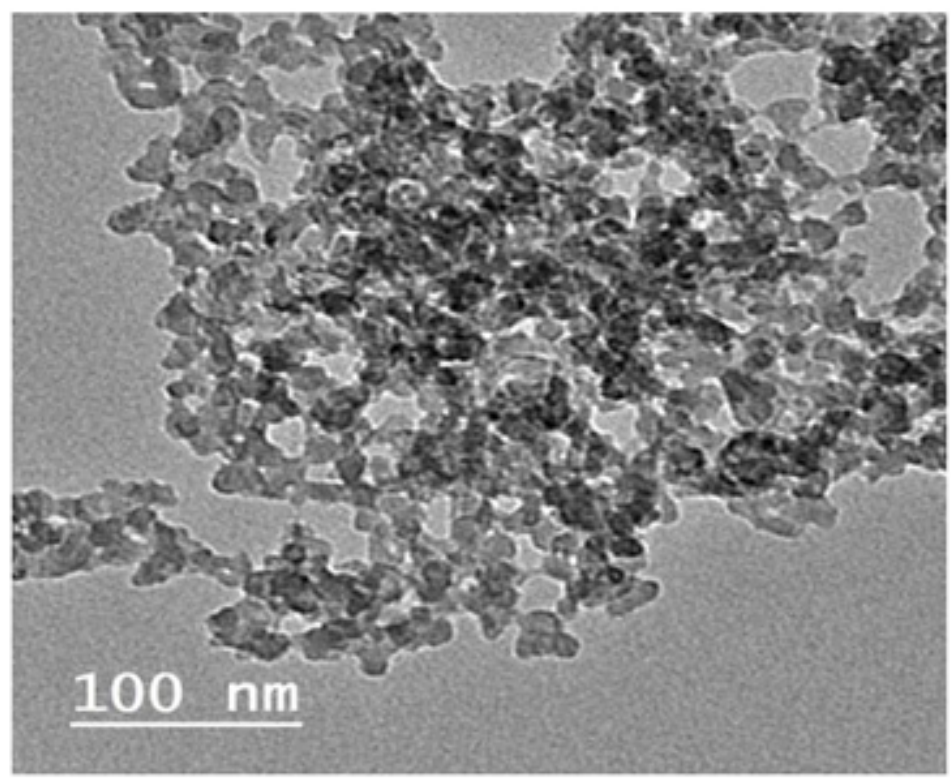

(B)

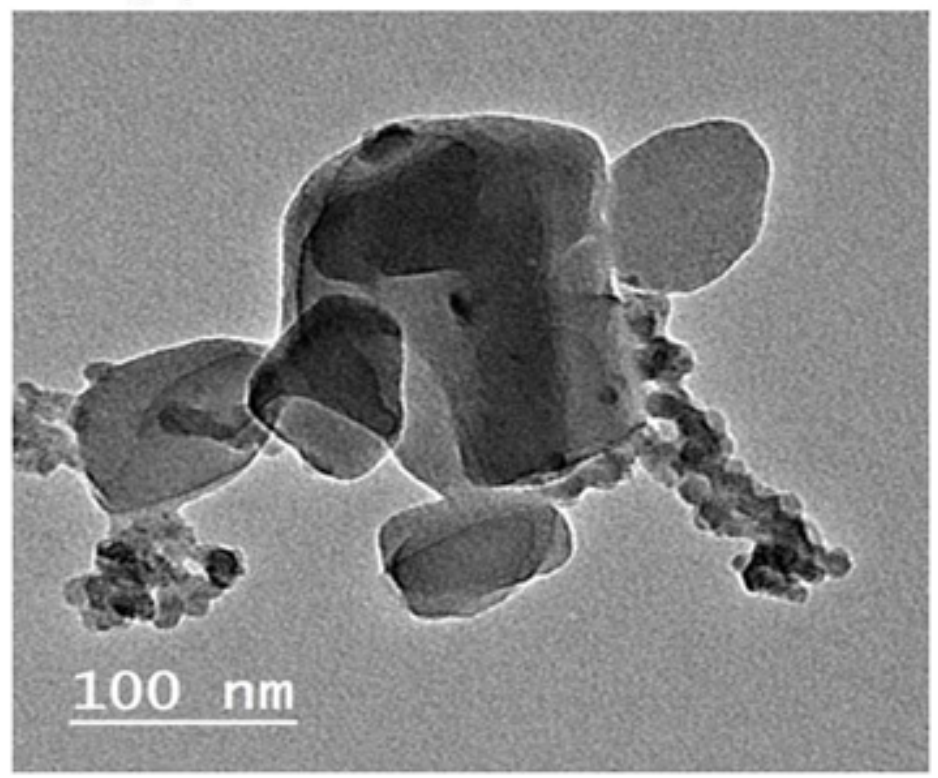

\section{Figure 1}


TEM images of (A) UiO-66 and (B) MUiO-66.

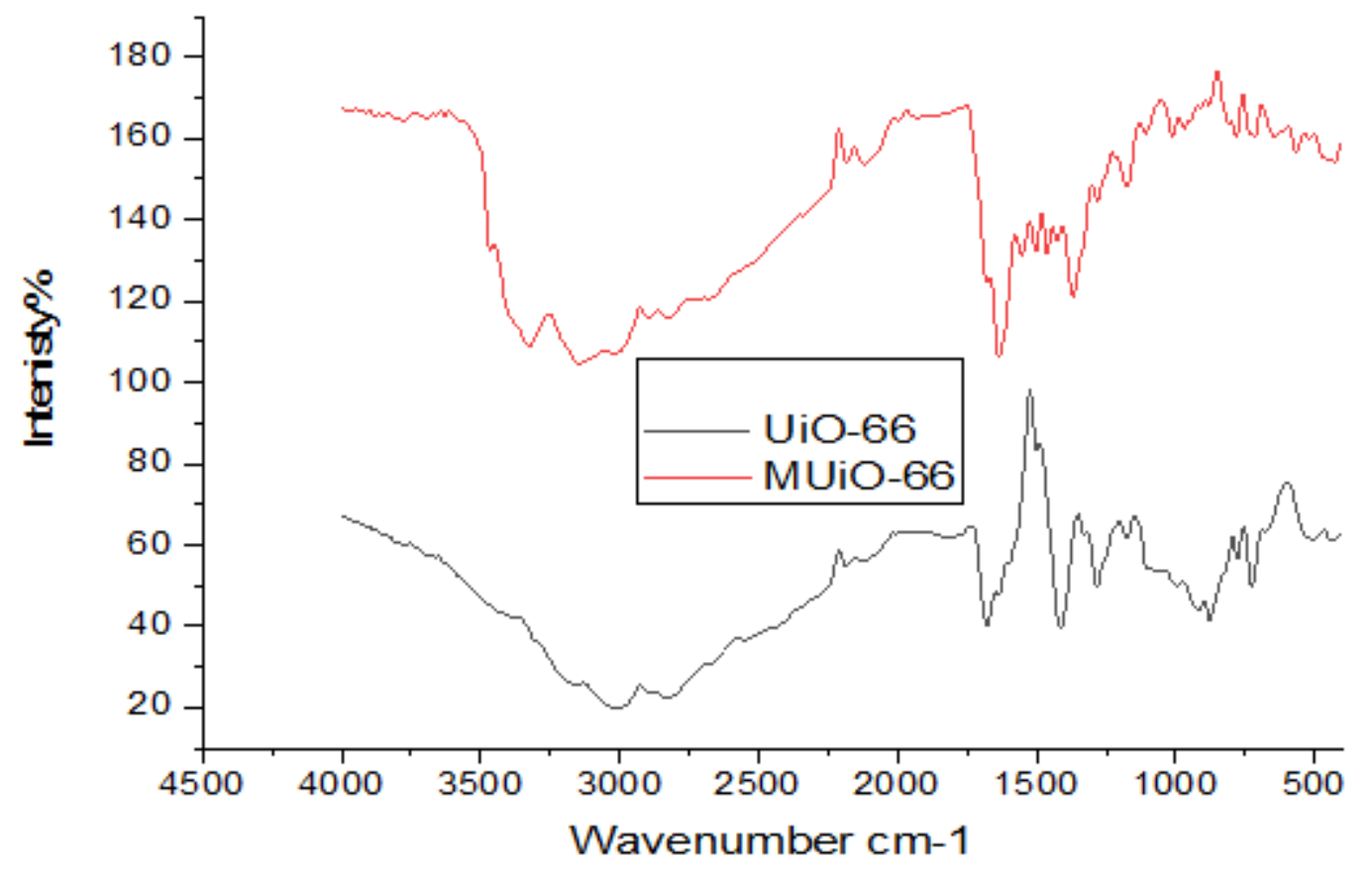

Figure 2

FTIR spectra of Ui0-66 and MUiO-66.

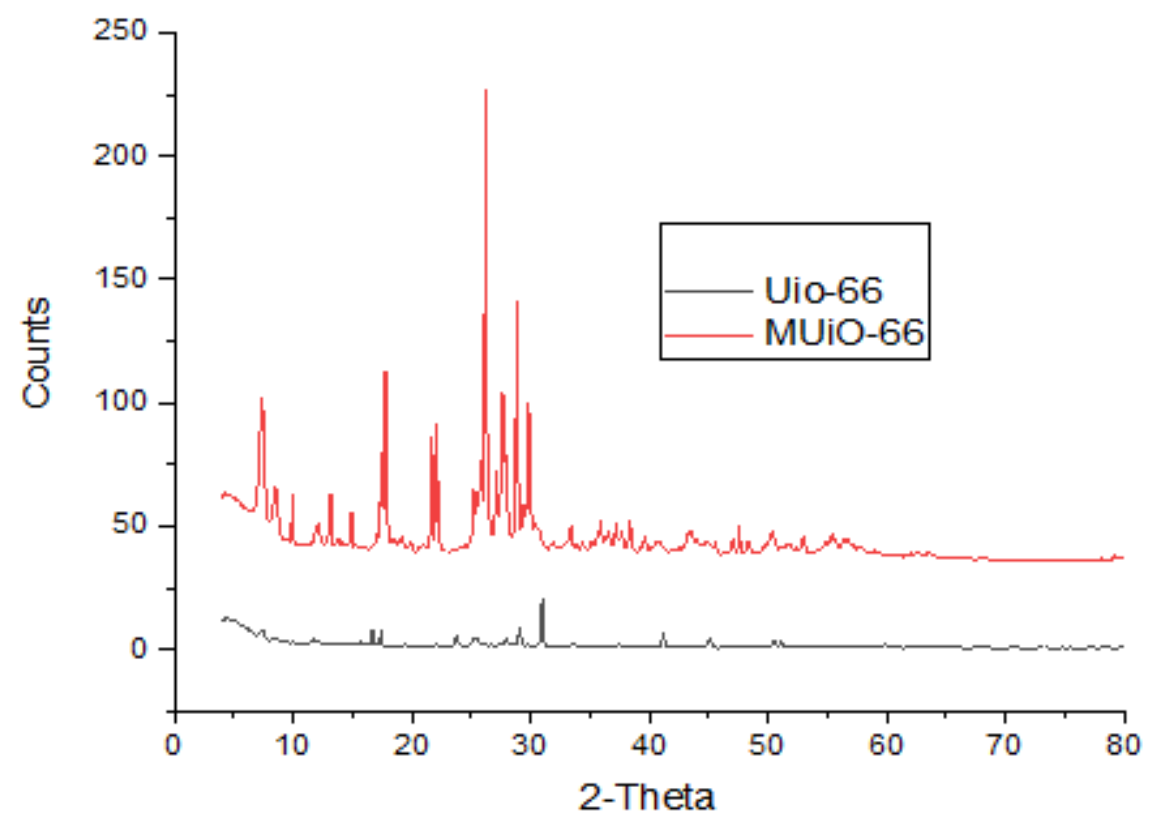

Figure 3

XRD patterns of UiO-66 and MUiO-66. 


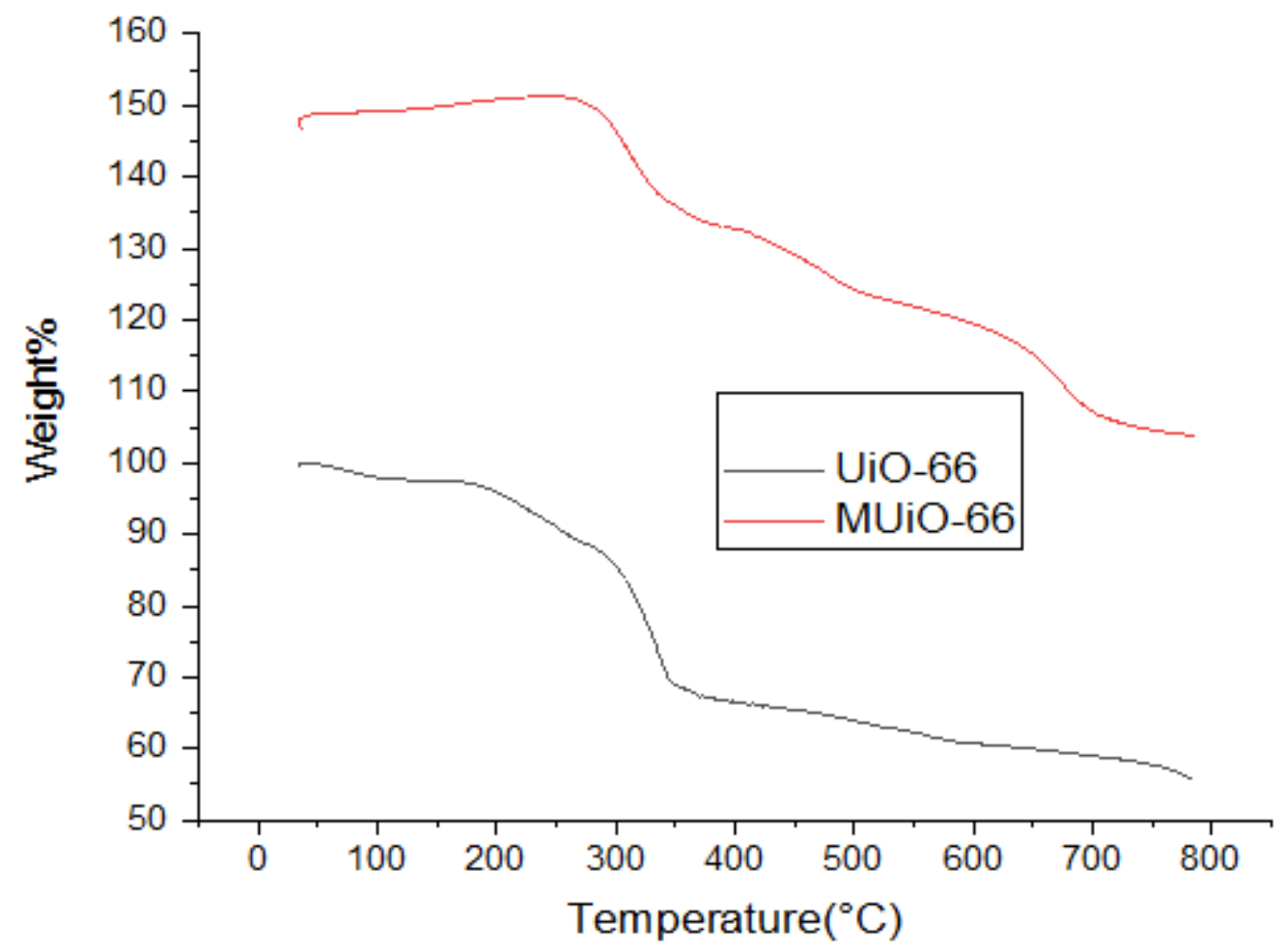

Figure 4

TGA curves of Ui0-66 and MUi0-66 samples.

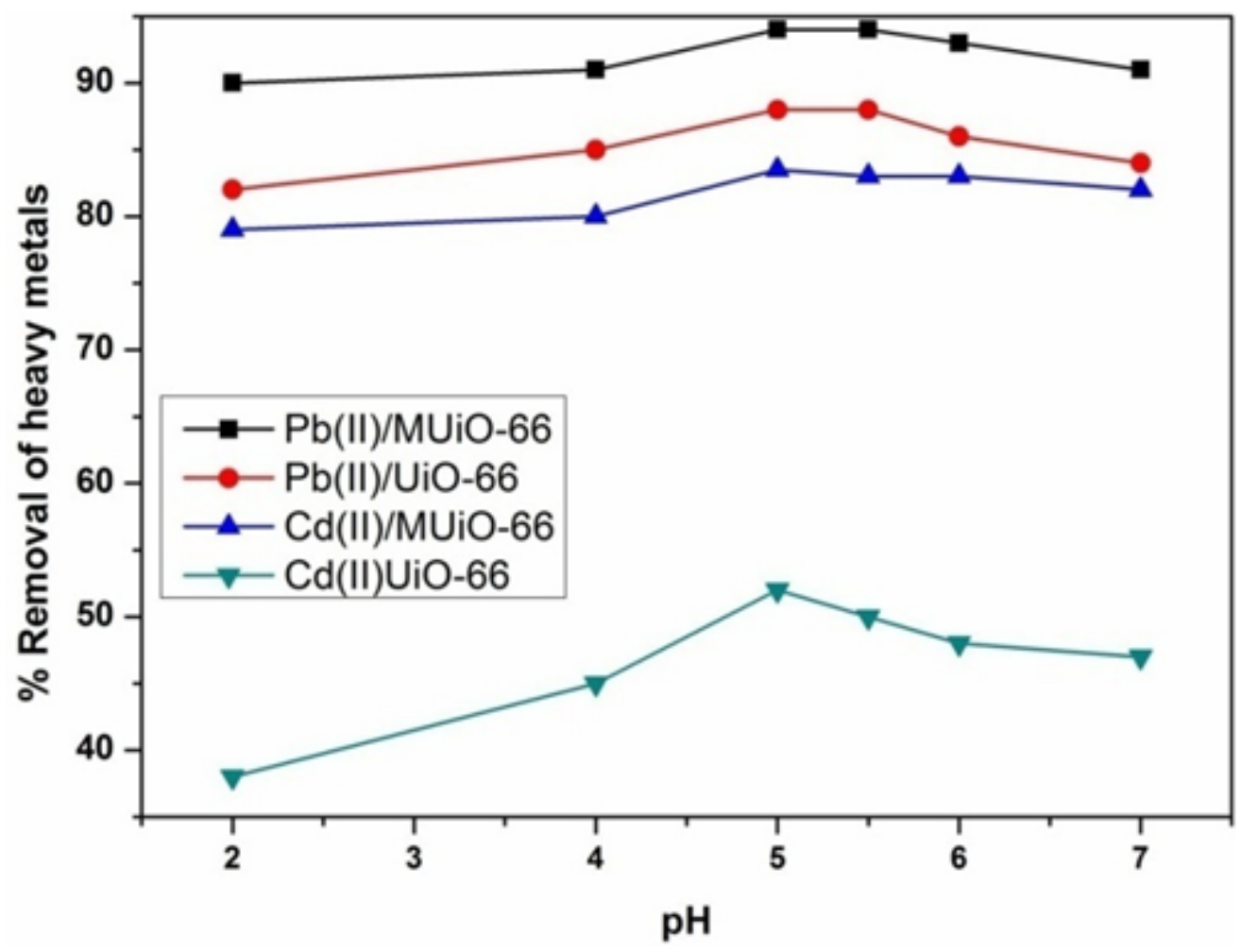

Figure 5 
Influence of $\mathrm{pH}$ on the removal of $\mathrm{Pb}$ and $\mathrm{Cd}$ (II) ions by the prepared MOF samples (adsorbent dose:1 g/L; Initial metal concentration:10 mg/L and Temp: 298K).
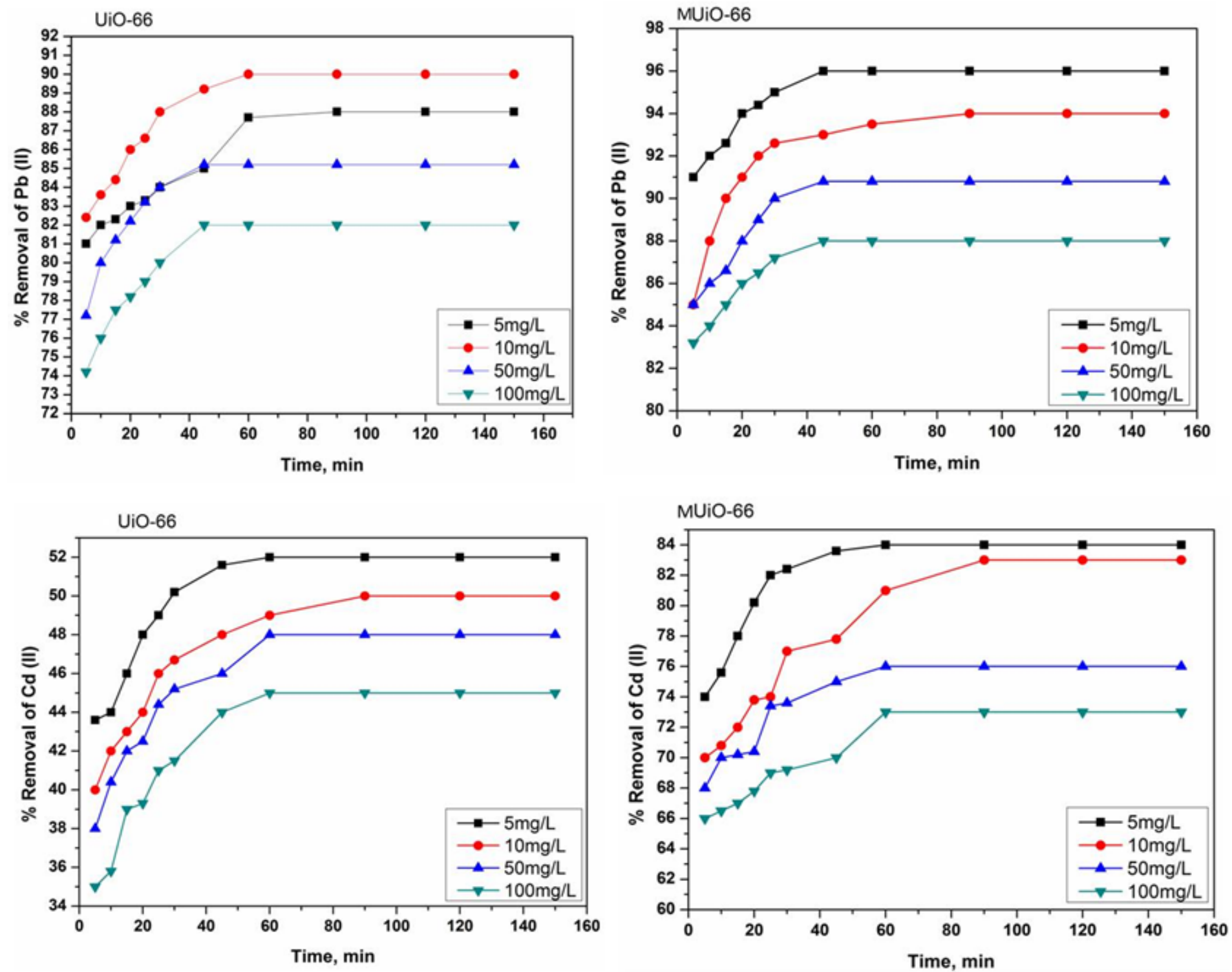

Figure 6

Effect of contact time and initial concentrations of both metal ions adsorbed by UiO-66 and MUiO-66 (adsorbent dose:1 g/L; Initial pH :5.5 and Temp: 298K). 


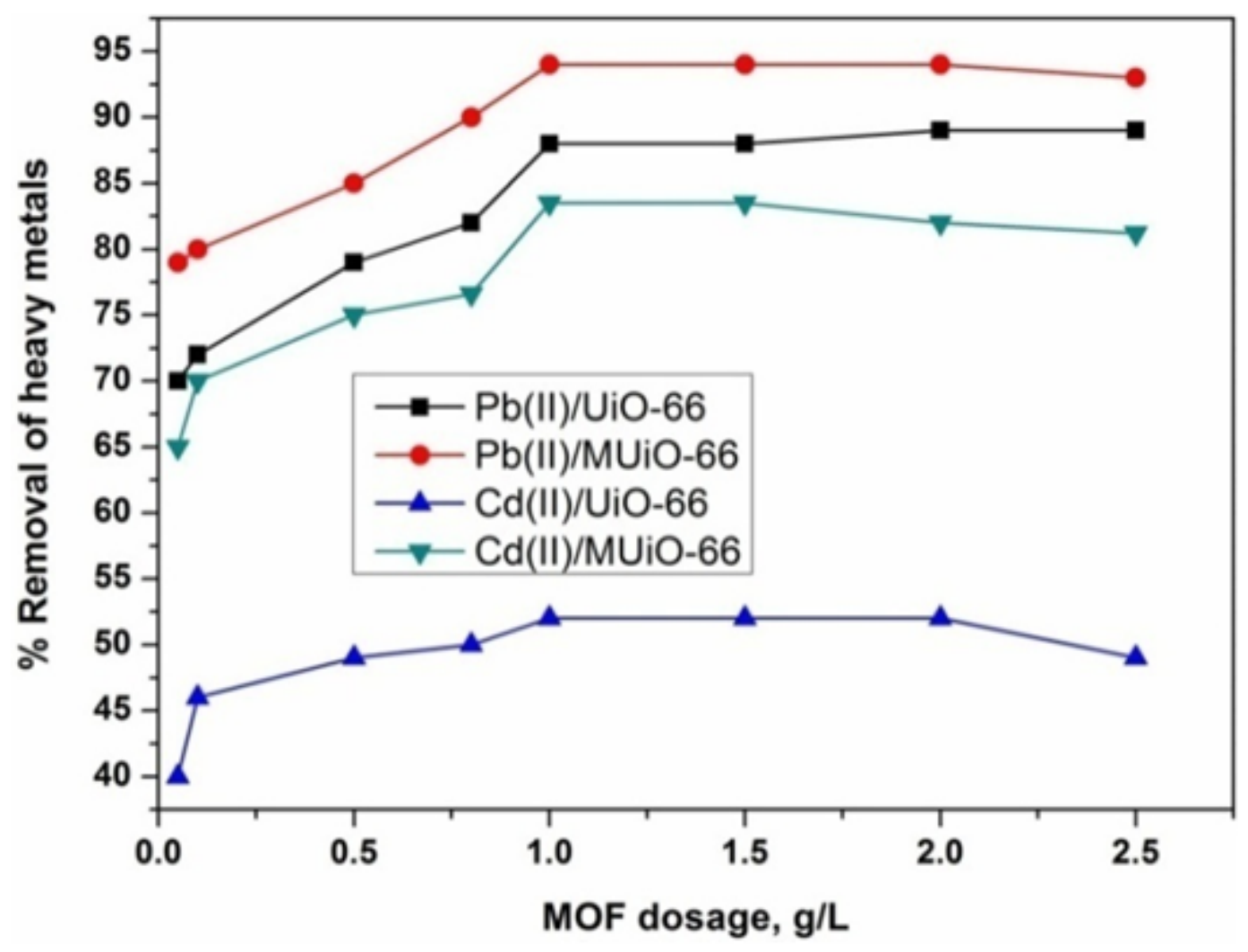

Figure 7

Effect of MOF dosage on the removal of $\mathrm{Pb}$ and $\mathrm{Cd}$ (II) ions (Initial pH : 5.5 and Temp: 298K). 


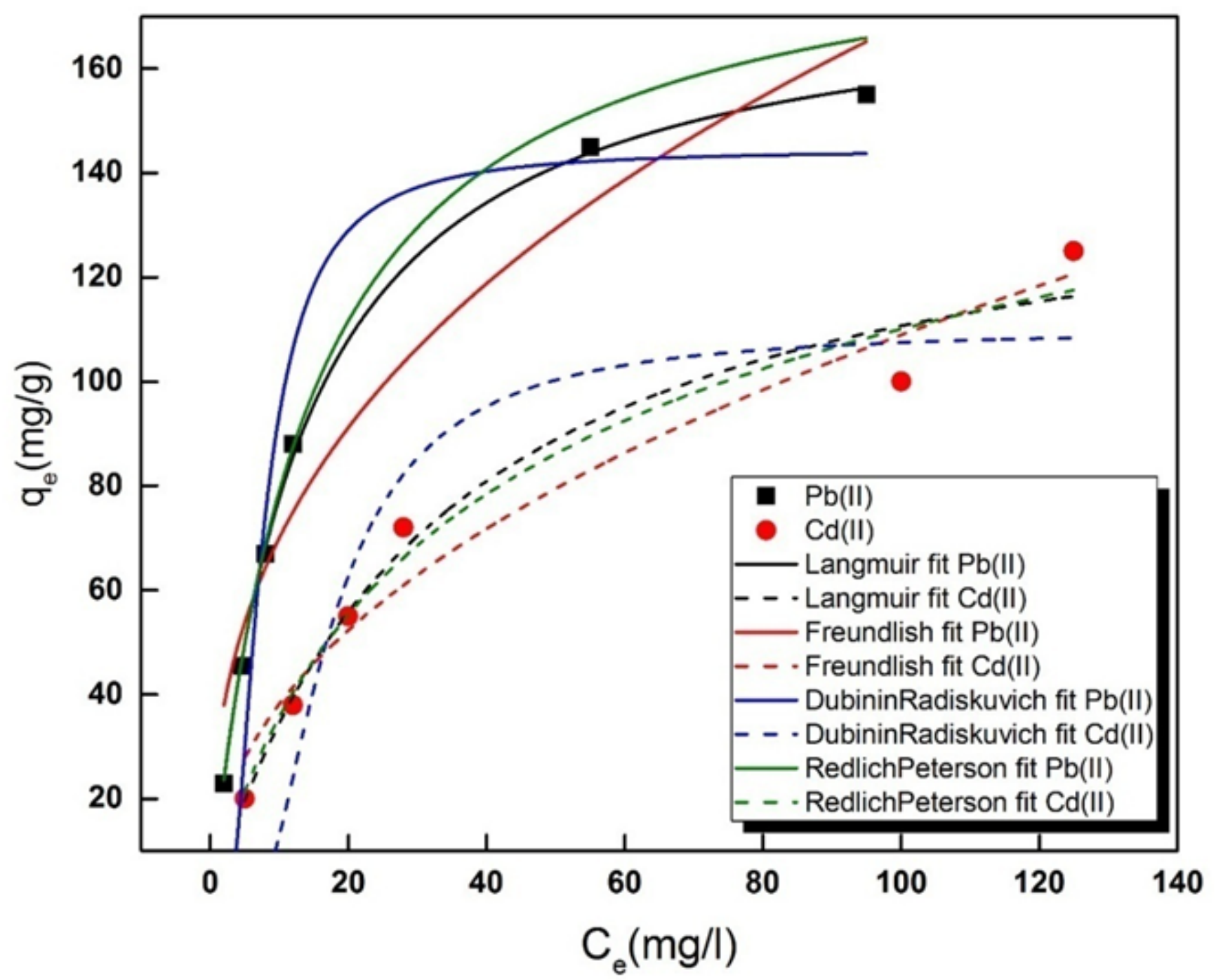

Figure 8

Adsorption isotherms of $\mathrm{Pb}$ and $\mathrm{Cd}$ (II) ions onto MUiO-66. 


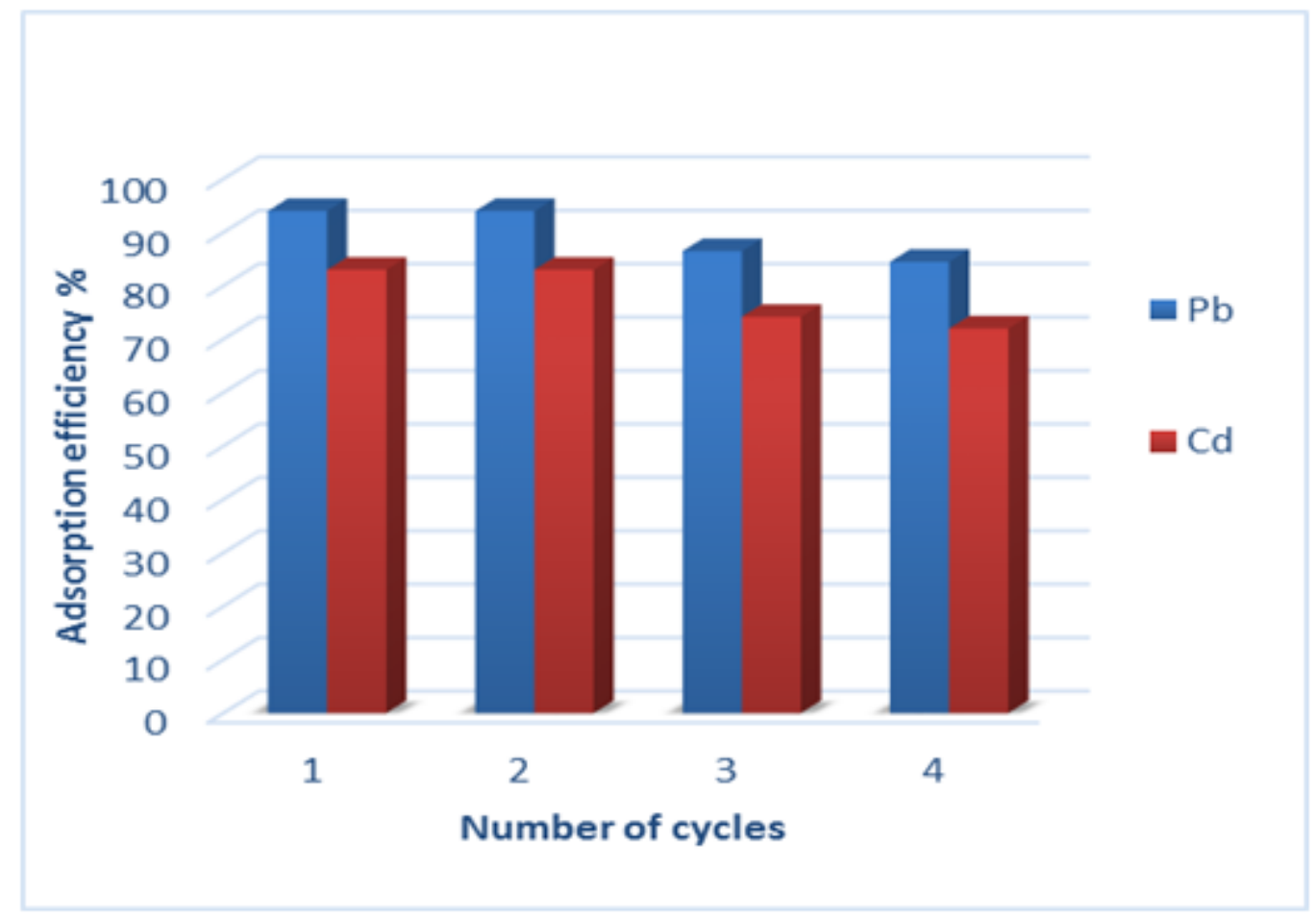

Figure 9

Reusability efficiency of MUiO-66 for desorption of $\mathrm{Pb}$ and $\mathrm{Cd}$ (II) ions through four 